\title{
IMPORTÂNCIA DA PRODUÇÃO PRIMÁRIA NO RETORNO DO ICMS NOS MUNICÍPIOS DO VALE DO TAQUARI/RS
}

\author{
Adalberto Schnorrenberger \\ Centro Universitário Univates \\ Julia Elisabete Barden \\ Centro Universitário Univates \\ Lucildo Ahlert \\ Centro Universitário Univates \\ Fernanda Cristina Wiebusch Sindelar \\ Centro Universitário Univates \\ Samuel Martim de Conto \\ Centro Universitário Univates
}

\section{IMPORTÂNCIA DA PRODUÇÃO PRIMÁRIA NO RETORNO DO ICMS NOS MUNICÍPIOS DO VALE DO TAQUARI/RS}

Resumo: Este artigo teve como objetivo dimensionar a produção primária nos municípios da Região do Vale do Taquari/RS (VT) e analisar sua importância ano retorno financeiro recebido pelos municípios através da transferência de recursos pelo Estado da cota-parte do ICMS. Para a realização da pesquisa foram utilizados dados extraídos de relatórios municipais e dados divulgados pela Secretaria da Fazenda do RS (SEFAZ). Ressalta que os resultados indicam que o ICMS é uma das principais fontes de receita para os municípios do VT e está vinculada à capacidade de geração de valor agregado das atividades econômicas, entres as quais se destaca a produção primária. Constata que essa atividade tem uma importância significativa nos critérios de repartição do ICMS. Por fim, sugere o desenvolvimento de políticas públicas que incentivem a atividade, de modo a ampliar a arrecadação tributária municipal e assim contribuir para a redução das disparidades intermunicipais.

Palavras-chave: Produção primária, ICMS, Vale do Taquari/RS.

IMPORTANCE OF PRIMARY PRODUCTION IN RETURN OF ICMS IN CITIES OF VALE DO TAQUARI/RS Abstract: The current essay aimed to estimate primary production in The Taquari Valley cities and investigate its relevance for the financial return through resource transfers of State Tax for Goods and Services - ICMS - by the State Government. In order to carry out the research data were collected from the city's reports as well as from reports published by The Farm Secretary of RS - SEFAZ. Results show that ICMS is one of the main sources of revenue for the Taquari Valley cities and it is connected to the capacity of aggregated value generation of economical activities among them primary production is essential. Notes that this activity is considerably relevant for the ICMS distribution criteria, the development of public policies promoting such activity is suggested in order to extend city tax collection so that it may contribute for the reduction of disparities among cities.

Keywords: Primary production, ICMS, Taquari Valley - RS. 


\section{INTRODUÇÃO}

A região do Vale do Taquari (VT), área de abrangência deste estudo, está localizada na região central do Rio Grande do Sul (RS), distante, em média, $150 \mathrm{~km}$ de Porto Alegre. Ela é constituída por 36 pequenos municípios, sendo sua população de 327.822 habitantes em 2010, 0 que representava aproximadamente $3 \%$ da população do RS (INSTITUTO BRASILEIRO DE GEOGRAFIA E ESTATÍSTICA, 2010).

Em relação aos aspectos econômicos, a região está alicerçada em atividades relacionadas à pequena produção rural baseada no modelo da agricultura familiar e mantém $26,15 \%$ do total da população residindo no meio rural (INSTITUTO BRASILEIRO DE GEOGRAFIA E ESTATÍSTICA, 2010), enquanto que no Estado, esse percentual é de $14,90 \%$. Contudo, ao desagregar esse dado em termos municipais, verifica-se que em 21 municípios, 0 percentual está acima de 50\%, chegando em alguns casos a ser superior a $80 \%$, como em Coqueiro Baixo e Forquetinha com 81,54\% e $81,20 \%$, respectivamente.

Em 2006, a região possuía 25.698 propriedades rurais, cujo tamanho médio era de 13,53 ha (INSTITUTO BRASILEIRO DE GEOGRAFIA E ESTATÍSTICA, 2009). A atividade primária caracteriza-se pela diversidade de culturas e criações, as quais, na maioria das vezes, são organizadas em sistema integrado com a indústria de alimentos (UNIVATES, 2011). Em consequência, a oferta de matéria-prima oriunda da agropecuária é destinada para a agroindústria processadora local, a qual representa uma das principais forças econômicas no Vale do Taquari com representatividade no mercado nacional e internacional, principalmente na produção de carne e de leite.

O VT possuía em 2009 um PIB de R\$ $6.327 .675,53$ que representava $2,93 \%$ do RS. Em termos de Valor Adicionado Bruto (VAB), $51,85 \%$ era formado no setor de serviços, $13,48 \%$ no setor da agropecuária, $34,67 \%$ na indústria de transformação, sendo que, neste setor, parcela significativa é representada por agroindústrias, cuja matéria-prima utilizada é oriunda do setor primário (UNIVATES, [20--?]).

Observa-se ainda, que a região apresenta desigualdades internas em relação à distribuição espacial da população, da geração e da apropriação da riqueza e das condições socioeconômicas, as quais também interferem na distribuição dos recursos públicos.

A forma vigente de distribuição da receita proveniente de impostos entre as esferas de governo foi determinada pela Constituição Federal (CF) de 1988. A partir de 1988 foi concedida mais autonomia aos municípios e, em contrapartida, ampliou suas responsabilidades. Em consequência, os municípios passaram a aumentar 0 seu controle sobre a arrecadação de suas receitas, já que por outro lado, ocorreu um aumento considerável em suas despesas.

$\mathrm{Na}$ classificação das receitas municipais, além das receitas próprias, decorrentes da cobrança de impostos municipais, taxas e contribuições de melhoria, as receitas de transferências de recursos por parte da União e dos Estados são de fundamental importância na composição do orçamento municipal.

Nesse grupo de receita, destacam-se as transferências decorrentes da cota-parte do Fundo de Participação dos Municípios (FPM), que é determinada pelo número de habitantes de cada município e da cota-parte do Imposto sobre Operações relativas à Circulação de Mercadorias e sobre a Prestação de Serviços de Transporte Interestadual e Intermunicipal e de Comunicação (ICMS). 0 rateio do ICMS se baseia em critérios de desempenho da economia municipal, com destaque para 0 Valor Adicionado Fiscal (VAF), que corresponde ao valor adicionado nas operações de entrada de mercadorias e/ou prestações de serviços em seu território em determinado ano civil.

Nesse sentido, o presente estudo integra a pesquisa Análise da Cadeia Produtiva da Carne Suína no Vale do Taquari/RS e foi realizado com o objetivo de dimensionar a produção primária nos 36 municípios da Região VT e identificar o impacto dessa atividade no retorno financeiro recebido pelos municípios 
por meio da transferência de recursos do Estado da cota-parte do ICMS.

0 presente artigo está estruturado em cinco seções. Além desta, na segunda seção são apresentadas algumas considerações acerca do assunto abordado. Na terceira, apresenta-se a metodologia de pesquisa utilizada para o desenvolvimento do trabalho. $\mathrm{Na}$ quarta seção são apresentados e analisados os resultados, e por fim, apresentam-se as considerações finais do estudo.

\section{A IMPORTÂNCIA DO ICMS PARA A RECEITA PÚBLICA MUNICIPAL}

A receita pública é fundamental no processo orçamentário, pois condiciona a capacidade governamental de realizar despesas. O Estado garante através dos mecanismos de política fiscal a entrada de recursos públicos, que servirão para desempenhar suas funções básicas.

As funções básicas podem ser classificadas em três. Primeiro, a função alocativa, relacionada ao fornecimento de bens públicos; segundo, a função distributiva, que diz respeito à distribuição de renda de forma justa entre a sociedade; e terceira, a função estabilizadora, onde o governo através da política econômica busca elevar o nível de emprego, a estabilidade dos preços e 0 crescimento econômico (GIAMBIAGI; ALÉM, 2008).

Segundo Stiglitz (apud PEREIRA, 2006, p. 35), as funções do Estado poderiam ser ampliadas, dada sua responsabilidade em:

[...] promover a educação, a fim de se construir uma sociedade mais igualitária e facilitar a estabilidade política; fomentar a tecnologia; oferecer suporte ao setor financeiro, principalmente através da disseminação da informação; investir em infraestrutura: instituições, direitos de propriedade, contatos, leis e políticas que promovam a concorrência; prevenir a degradação ambiental e promover 0 desenvolvimento sustentável; e criar e manter uma rede de seguridade social.
Assim, na administração pública, a receita e a despesa orçamentária são resultados do montante do valor que o Estado se apropria da sociedade por intermédio da tributação, para em contrapartida oferecer bens e serviços aos cidadãos. No entanto, cabe destacar que é a previsão da receita que condiciona a capacidade governamental em fixar a despesa pública, e por este motivo, ela assume um papel central para os entes públicos (BRASIL, 2011).

A receita orçamentária é caracterizada como a disponibilidade de recursos financeiros arrecadados durante um ano, a qual viabiliza a execução das funções públicas. Elas são fontes de recursos utilizadas pelo Estado para atender as necessidades e demandas da sociedade, através da implementação de programas e ações (BRASIL, 2011).

No Brasil, a CF 1988 alterou de maneira significativa a distribuição da receita proveniente de impostos entre as esferas de governo, transformou os municípios em entes federativos com autonomia política, legislativa, administrativa e financeira, responsáveis pela execução da política urbana e pela prestação de serviços públicos, principalmente nas áreas sociais, ampliando suas responsabilidades. Em contrapartida, determinou uma ampliação das transferências de recursos por parte da União e dos Estados aos Municípios.

Conforme a Lei 4320, de 17 de março de 1964, as receitas públicas dividem-se em duas categorias econômicas: as receitas correntes e as receitas de capital (Quadro 1). As receitas correntes são aquelas arrecadadas dentro do exercício, que aumentam as disponibilidades financeiras do Estado e, em geral, geram um efeito positivo sobre o patrimônio líquido.

Classificam-se como Correntes as receitas provenientes de Tributos; de Contribuições; da exploração do patrimônio estatal (Patrimonial); da exploração de atividades econômicas (Agropecuária, Industrial e de Serviços); de recursos financeiros recebidos de outras pessoas de direito público ou privado, quando destinadas a atender despesas 
classificáveis em Despesas Correntes (Transferências Correntes); por fim, demais receitas que não se enquadram nos itens anteriores (Outras Receitas Correntes). (BRASIL, 2011, p. 14).

\section{Quadro 1 - Classificação da Receita Pública}

\begin{tabular}{|l|ll|}
\hline Receitas Correntes & Receita de Capital \\
\hline Receita Tributária & Operações de Crédito \\
\hline $\begin{array}{l}\text { Receita de } \\
\text { Contribuições }\end{array}$ & Alienação de Bens & \\
\hline Receita Patrimonial & $\begin{array}{l}\text { Amortização de } \\
\text { Empréstimos }\end{array}$ \\
\hline Receita Agropecuária & $\begin{array}{l}\text { Transferências de } \\
\text { Capital }\end{array}$ \\
\hline Receita Industrial & $\begin{array}{l}\text { Outras Receitas de } \\
\text { Capital }\end{array}$ \\
\hline Receita de Serviços & \\
\hline $\begin{array}{l}\text { Transferências } \\
\text { Correntes }\end{array}$ & \\
\hline $\begin{array}{l}\text { Outras Receitas } \\
\text { Correntes }\end{array}$ & \\
\hline
\end{tabular}

Fonte: Elaborado pelos autores, a partir de: BRASIL. Ministério da Fazenda. Secretaria do Tesouro Nacional. Manual de Contabilidade Aplicada ao Setor Público: parte I - procedimentos contábeis orçamentários. 4. ed. Brasília, DF, 2011. Disponível em:<http://goo.gl/c9zSt>. Acesso em:1 mar. 2012.

Por outro lado, as receitas de capital se diferenciam destas por não provocarem efeito sobre o patrimônio líquido. Elas são resultado da geração de

[...] recursos financeiros oriundos da constituição de dívidas e da conversão, em espécie, de bens e direitos, quanto de recursos recebidos de outras pessoas de direito público ou privado (BRASIL, 2011, p. 14).

Dentro desse contexto, as receitas correntes registradas nos orçamentos municipais são as decorrentes da arrecadação de receitas tributárias próprias, entre as quais se destaca a cobrança do Imposto Predial e Territorial Urbano (IPTU), do Imposto sobre Serviços de Qualquer Natureza (ISSQN) e do Imposto sobre Transmissão de Bens Intervivos (ITBI), e as transferências correntes recebidas da União e dos Estados. Por parte da União, destaca-se o recebimento do repasse do FPM e das transferências do Sistema Único de Saúde (SUS) e do Fundo de Manutenção e Desenvolvimento da Educação Básica e de Valorização dos Profissionais da Educação (FUNDEB), direcionadas especificamente para atender a execução dos serviços de saúde e de educação básica, segundo normas rígidas. $\mathrm{E}$, dentre os principais repasses dos Estados estão as transferências do Imposto sobre Circulação de Mercadorias e Prestação de Serviços de Transporte Interestadual e Intermunicipal e de Comunicação (ICMS) e do Imposto sobre a Propriedade de Veículos Automotores (IPVA) (PINHEIRO, 2009).

Assim, as transferências correntes cumprem um papel fundamental nos orçamentos municipais, pois garantem a realização de suas atividades. Como elas são decorrentes principalmente de repasses constitucionais, caracterizam-se como uma fonte estável de receita para os municípios, principalmente para os menores onde a atividade econômica é pouco desenvolvida, auxiliando a reduzir as disparidades regionais.

Em relação à distribuição do ICMS, objeto de estudo deste trabalho, a CF/1988 estabeleceu que os municípios brasileiros possuem direito a $25 \%$ do total arrecadado pelos Estados. Dessa forma, embora o ICMS seja um imposto estadual, apenas $75 \%$ do valor arrecadado pode ser gasto pelos Estados, e 0 restante deverá ser repassado aos municípios, por meio de critérios compostos por variáveis como: população, área, mortalidade infantil, evasão escolar, atividade primária e 0 VAF.

No Rio Grande do Sul, a legislação sobre a incidência do ICMS está definida na Lei 8820, de 27 de janeiro de 1989 e regulamentada através do Decreto 37699 , de 26 de agosto de 1997. A metodologia de cálculo que determina 0 índice de participação de cada município na parcela de $25 \%$ do produto da arrecadação do ICMS está descrita na Lei $n^{0} 11.038$, de 14 de novembro de 1997, conforme os seguintes critérios: 
Tabela 1 - Critérios de rateio da Cota-parte do ICMS a ser distribuída aos municípios

\begin{tabular}{lr}
\hline \multicolumn{1}{c}{ Parâmetro } & Peso (\%) \\
\hline Valor Adicionado Fiscal (VAF) & 75,0 \\
População & 7,0 \\
Área & 7,0 \\
Número de propriedades rurais & 5,0 \\
Pontuação no Projeto Parceria & 0,5 \\
Produtividade primária & 3,5 \\
Relação inversa ao valor adicionado & 2,0 \\
fiscal "per capita" &
\end{tabular}

Fonte: RIO GRANDE DO SUL. Secretaria da Fazenda. Lei $\mathrm{n}^{0} 11.038$ de 14 de novembro de 1997. Dispõe sobre a parcela do produto da arrecadação do Imposto sobre Operações Relativas à Circulação de Mercadorias e sobre Prestações de Serviços de Transporte Interestadual e Intermunicipal e de Comunicação (ICMS) pertencente aos municípios. Diário Oficial do Estado, Porto Alegre, 1997. Disponível em:<http://www.bvsde.paho.org/bvsacd/cd38/Bra sil/L11038.pdf>. Acesso em: 18 nov. 2011.

Conforme pode ser observado na Tabela 1, o critério de maior importância é a participação do VAF. Seu valor é obtido através da soma do valor que se acrescenta (adiciona) nas operações relativas à circulação de mercadorias e prestações de serviços realizados em seu território, em determinado ano, ou seja, corresponde ao valor que é somado ao valor de compra. Ele é apurado pela Secretaria Estadual da Fazenda do Rio Grande do Sul (SEFAZ) com base nas declarações anuais apresentadas pelas empresas e produtores rurais estabelecidas nos respectivos municípios.

A indústria e o comércio apuram o valor adicionado fiscal pela diferença entre saídas e entradas ocorridas durante um ano de referência ou parte daquele mesmo ano, nos casos de inscrição nova ou de baixa. No caso dos produtores rurais, considera-se integralmente 0 valor de suas vendas com exceção das transferências e depósitos, descontadas as compras de produtores rurais de outros municípios.

O cálculo do índice de VAF resulta da média das representatividades do valor adicionado fiscal de cada Município relativo aos últimos dois anos, isto é, somando-se as representatividades (relação percentual) do VAF de cada Município dos últimos anos em relação à arrecadação do Estado.

Os demais parâmetros são fornecidos por Órgãos Oficiais. Para o cálculo do segundo critério, considera-se a relação percentual entre a população residente no município e a residente no Estado. 0 terceiro critério baseiase na relação percentual entre a área do município, multiplicando-se por 3 (três) as áreas de preservação ambiental, as áreas de terras indígenas e aquelas inundadas por barragens, exceto as localizadas nos municípios sedes das usinas hidrelétricas, e a área calculada do Estado, em quilômetros quadrados. 0 quarto critério compara o número de propriedades rurais cadastradas no município e o das cadastradas no Estado em termos percentuais. 0 quinto critério é determinado pela relação percentual entre a pontuação de cada município no Programa de Integração Tributária (PIT), instituído por lei, e 0 somatório de todas as pontuações de todos os municípios, apuradas pela Secretaria da Fazenda do Estado. O sexto critério considera a relação percentual entre a produtividade primária do município e a do Estado. E por fim, ainda se considera a relação inversa ao VAF per capita dos municípios, conforme as mesmas metodologias utilizadas nos incisos I e II deste artigo.

Assim, observa-se que o valor de repasse das transferências está diretamente relacionado ao valor adicionado gerado em cada município e, em consequência, do seu nível de atividade econômica.

Monastério (2004) critica essa forma de rateio, descreve as regras de repartição como injustas, uma vez que elas podem contribuir para a ampliação das diferenças regionais, visto que as regiões mais pobres são as que menos recebem retorno do ICMS. Além disso, segundo 0 autor, em alguns casos o produto pode ser gerado em um determinado município, mas a sua apropriação pode ocorrer por residentes de outros municípios, havendo assim disputas entre os envolvidos para a sua contabilização.

Contudo, enquanto não houver alteração na forma de rateio, e os critérios vigentes forem mantidos, cabe aos municípios desenvolverem 
políticas públicas que incentivem a ampliação de suas atividades econômicas, de forma a ampliar sua participação no rateio do VAF do Estado, e assim, garantir a geração de receitas públicas.

\section{PROCEDIMENTOS METODOLÓGICOS}

De acordo com o objetivo da pesquisa, esta é do tipo exploratória e descritiva. A pesquisa bibliográfica foi realizada em livros, revistas e artigos científicos e representa a base da pesquisa exploratória. A pesquisa documental teve como base registros das prefeituras municipais e dados fornecidos pelo Estado. Os registros municipais foram obtidos através de consultas ao banco de dados dos produtos comercializados através do Talão de Produtor Rural, que são digitados e transmitidos eletronicamente à SEFAZ. Os dados do Estado referem-se aos publicados pela SEFAZ referente à produção da agropecuária e índices de retorno do ICMS usados para a remessa de recursos públicos por município. Além disso, foram usados dados do Censo Agropecuário do IBGE e banco de dados de pesquisas anteriores sobre a região do VT.

A população da pesquisa é formada pelos 36 municípios que compõem o VT, sendo a organização dos dados feita em planilhas eletrônicas, onde foram tabulados e apresentados através de tabelas e gráficos.

Em termos de limitações do estudo, citam-se os dados vinculados ao município de Lajeado, os quais se encontram danificados no Sistema da Prefeitura, não permitindo o seu acesso. Ressalta-se, porém, que a produção agrícola de Lajeado representa aproximadamente $1 \%$ do total da região do VT. Assim, devido a pouca representatividade destes dados, entendeu-se que a inexistência dos mesmos não compromete a compreensão da importância da produção primária para a Região.

\section{ANÁLISE DOS DADOS}

A receita proveniente da transferência da cota-parte do ICMS pelo Estado aos municípios é uma importante fonte de receita, a qual auxilia na execução das funções de cada governo. Em 2010, nos municípios da região do VT, essa receita teve uma participação média de $27,22 \%$ da receita orçamentária anual. Enquanto que em alguns municípios a transferência representou mais de $40 \%$ do total da receita orçamentária, como é o caso dos municípios de Westfália $(42,31 \%)$, Roca Sales $(40,88 \%)$ e Capitão $(40,38 \%)$, em outros, teve uma menor participação, como em Progresso (17,88\%), Doutor Ricardo $(18,81 \%)$ e Putinga (18,90\%) (Apêndice A).

A receita do ICMS está diretamente vinculada com a capacidade de geração de valor agregado nos municípios em decorrência de suas atividades econômicas. Isso ocorre, pois, dentre os critérios de repartição do ICMS, o VAF tem $75 \%$ de contribuição.

Nesse sentido, o Apêndice B apresenta - VAF para os municípios da região do VT, para o período de 2007 a 2009, os quais contribuíram para a constituição dos índices de retorno do ICMS para os exercícios de 2010 e 2011. No período analisado, a região apresentou um desempenho favorável, com crescimento médio anual de $8 \%$. Em 2009, o VAF da Região foi igual a $\mathrm{R} \$ 4.721 .916 .135,00$, isso representou um crescimento de $6,14 \%$ se comparado com o ano anterior e 16,64\% em relação a 2007. O município que apresentou 0 maior crescimento do VAF no período entre 2007 e 2009 foi o município de Canudos do Vale com um crescimento de $69,41 \%$. Por outro lado, o município de Muçum apresentou um decréscimo de $30,05 \%$ de sua produção no mesmo período.

Considerando a importância relativa do VAF por município em 2009, é possível observar que $53,5 \%$ foram gerados em cinco municípios: Lajeado, Estrela, Teutônia, Arroio do Meio e Encantado. Dessa forma, identificase uma concentração da atividade produtiva $e$ que tem se intensificado ao longo dos anos, pois em 2007 este conjunto de municípios era responsável por $50,8 \%$ da geração do VAF. Percebe-se, assim, a existência de um quadro de disparidade entre as economias dos municípios que compõem a Região, uma vez que a maior parte dos municípios contribuem 
pouco na geração do valor do VAF (Gráfico 1). A justificativa pode ser 0 fato dos municípios menores terem sua base econômica alicerçada na produção primária, com menor participação dos setores industrial e de serviços.

Em 2007, a produção primária contribuiu com $33,43 \%$ do VAF, sendo o valor gerado de $\mathrm{R} \$$ 1.353.201.171,00. No ano seguinte, a produção apresentou um crescimento, correspondeu a $36,48 \%$ do VAF, e em 2009, reduziu para $34,74 \%$. A diminuição ocorreu devido a uma redução da participação do setor primário na constituição do VAF, pois em termos de valor absoluto, a produção não diminuiu, pelo contrário, apresentou um crescimento de 1,09\% entre 2008 e 2009 (Apêndice C).

O município com maior destaque no crescimento médio no período entre 2007 e 2009 foi 0 município de Canudos do Vale $(31,47 \%)$, seguido pelos municípios de Colinas

\section{Gráfico 1 - Importância Relativa do Valor Adicionado Fiscal por município do Vale do Taquari - 2007 a 2009}

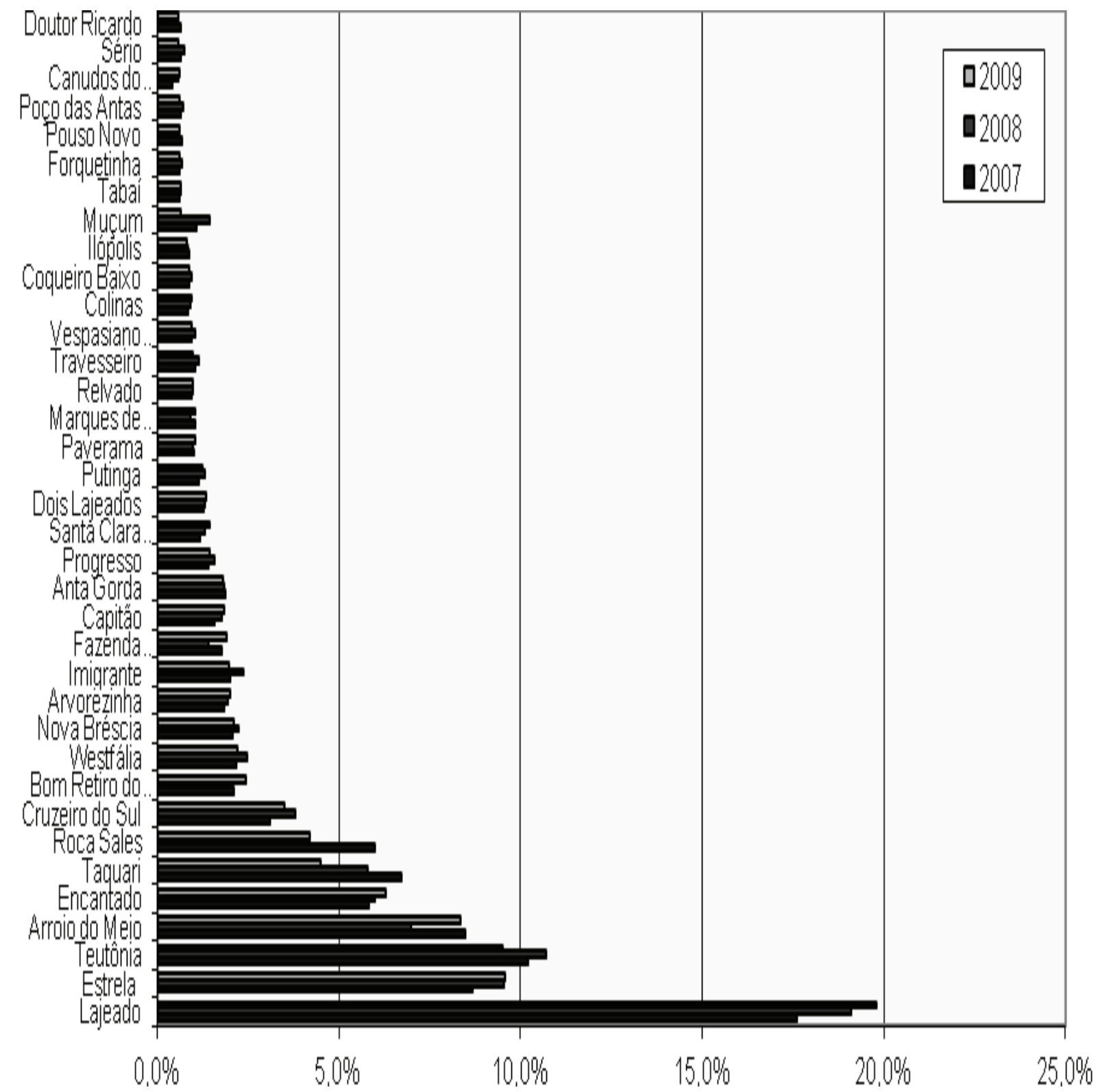

Fonte: Elaborado pelos autores, com base em dados da SEFAZ (RIO GRANDE DO SUL,1997). 


\section{Gráfico 2 - Importância relativa do Valor da Produção Primária em relação ao Valor Adicionado Fiscal no Vale do Taquari - 2007 a 2009}

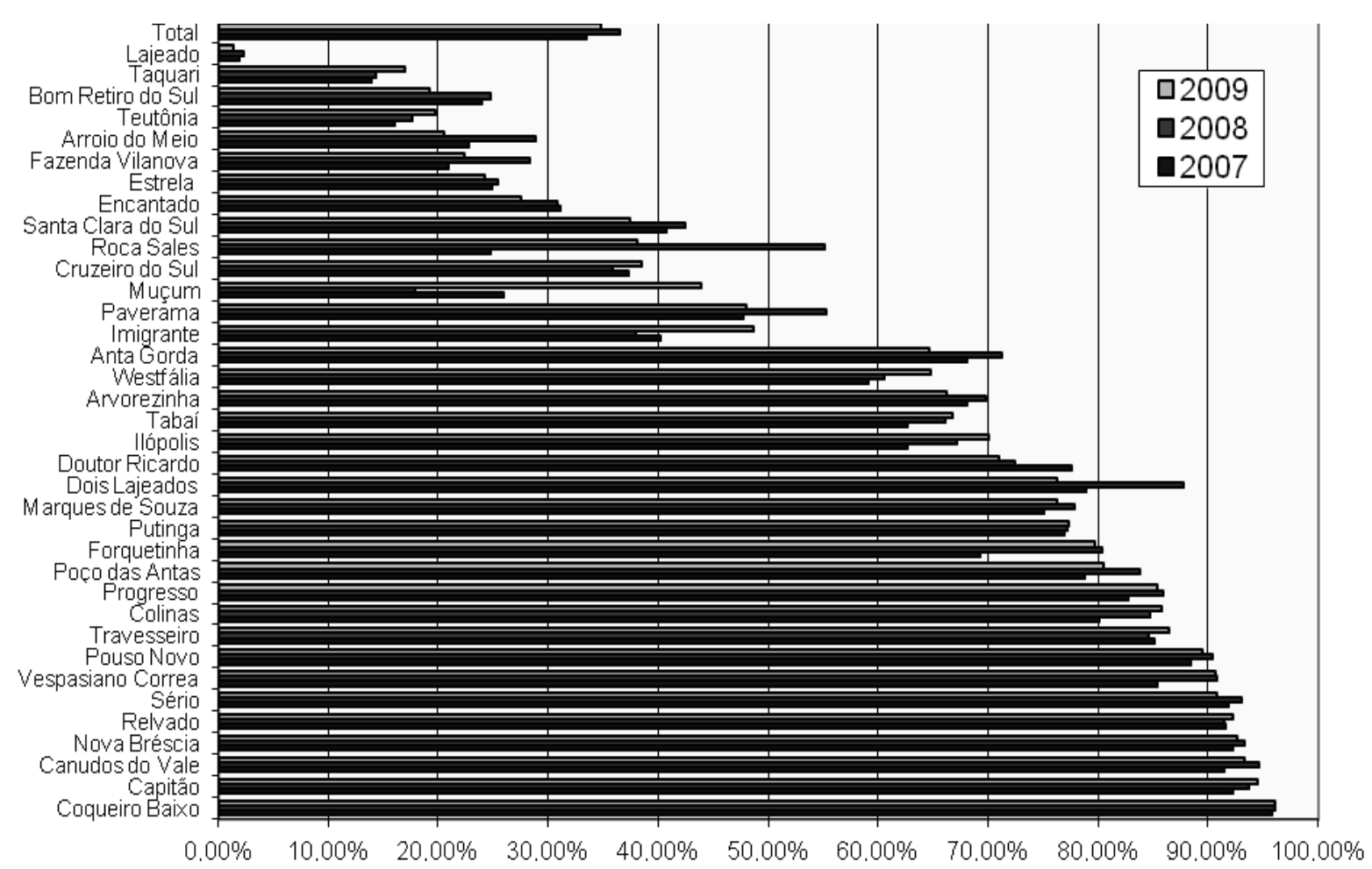

Fonte: Elaborado pelos autores com base em dados da SEFAZ (RIO GRANDE DO SUL,1997).

$(18,26 \%)$ e Capitão $(17,93 \%) .0$ desempenho destes municípios esteve diretamente relacionado com 0 crescimento da produção primária. Em 2009, o valor da produção primária nestes municípios contribui com $93,35 \%, \quad 85,80 \%$ e $94,54 \%$ do VAF, respectivamente.

No município de Coqueiro Baixo, a produção primária apresentou a maior importância relativa se comparada ao VAF em 2009 , pois $96,10 \%$ foram provenientes deste setor. Esta característica também pode ser observada em outros municípios, uma vez que em 11 municípios a produção primária apresentou uma importância relativa superior a $80 \%$. Por outro lado, os municípios onde o setor primário tem menor importância para a geração do VAF foram os municípios de Lajeado, 1,43\%, Taquari 16,93\% e Bom retiro do Sul, 19,27\% (Gráfico 2).

Além disso, analisando a participação relativa da produção primária municipal em relação à produção primária total da região em 2009, observa-se que os municípios que apresentaram maior participação foram Estrela $(6,65 \%)$, Nova Bréscia $(5,62 \%)$ e Teutônia $(5,39 \%)$. Por outro lado, os municípios com menor contribuição no valor da produção primária regional foram os municípios de Lajeado $(0,81 \%)$, Muçum $(0,82 \%)$ e Doutor Ricardo (1,21\%).

A partir das informações é possível observar a importância que a produção primária tem em alguns municípios e qual sua relação com o retorno do ICMS para estes municípios. Embora esse retorno esteja associado a vários critérios de rateio, os municípios, ao incentivarem as atividades primárias, estão contribuindo não apenas para 0 aumento do VAF, mas também para a ampliação do número de propriedades e da produtividade agrícola, os quais juntos representam $8,5 \%$ em relação aos fatores considerados no cálculo do índice de retorno do ICMS (Tabela 1). Por esse motivo, a produção primária tem contribuído de maneira diferente nos municípios. 


\section{Gráfico 3 - Percentual do retorno relativo da produção primária do ICMS por município no VT - 2009 a 2011}

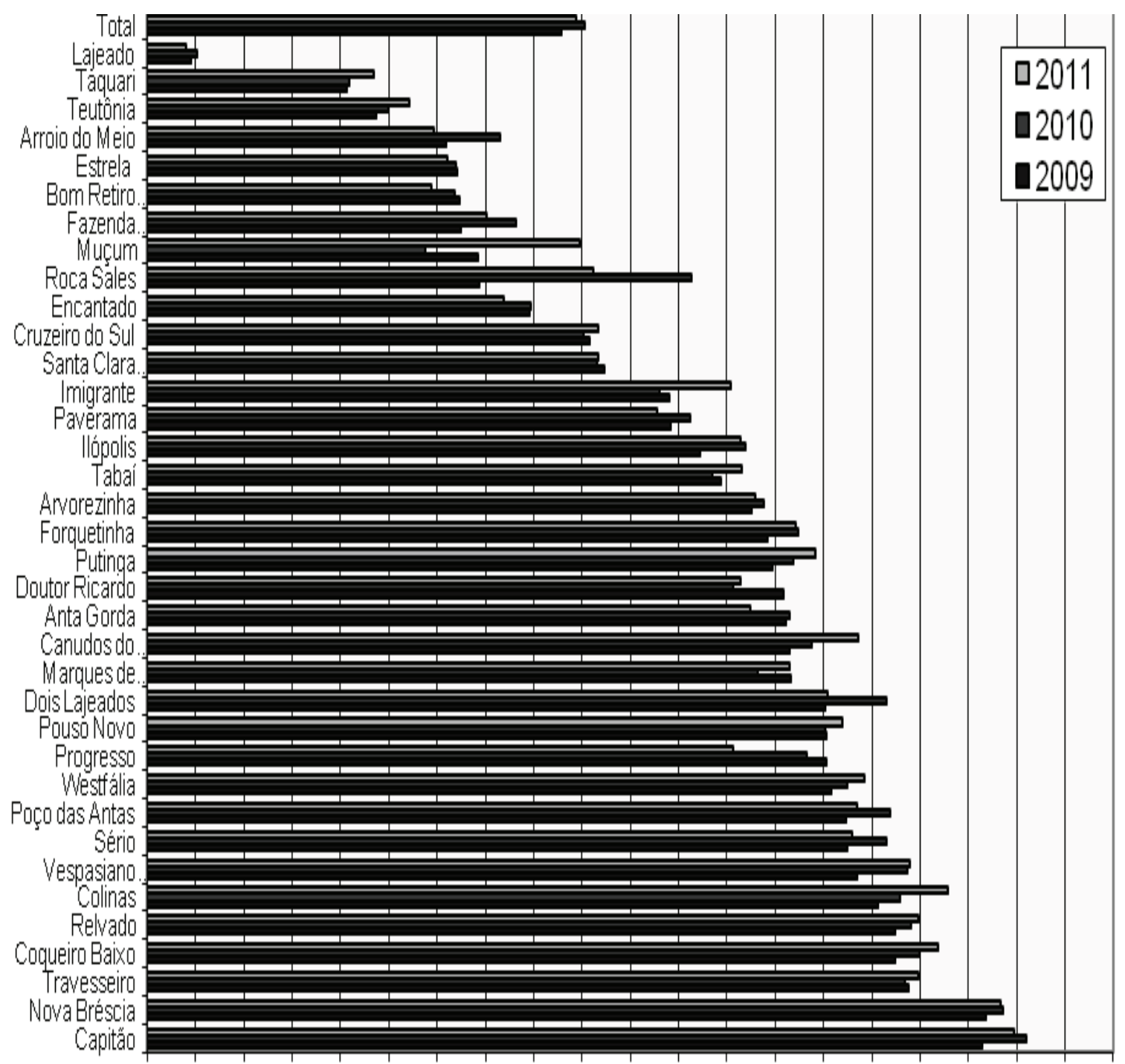

0,00 5,00 10,00 15,0020,0025,00 30,00 35,0040,0045,00 50,0055,00 60,00 65,0070,00 75,00 80,0085,00 90,0095,00100,00

Fonte: Elaborado pelos autores com base em dados da SEFAZ (RIO GRANDE DO SUL,1997).

Em termos percentuais, o retorno de ICMS gerado pela produção primária na Região em 2011 foi de 44,42\% (Gráfico 3). Entretanto, este desempenho é distinto entre os municípios. Enquanto que nos municípios de Capitão, Nova Bréscia e Colinas o retorno do ICMS gerado pela produção primária representou $89,74 \%, 88,28 \%$ e $82,84 \%$, respectivamente, do valor total recebido de ICMS como transferência do Estado, nos municípios de Lajeado, Taquari e Teutônia, essa participação foi inferior, representando apenas $3,96 \%, \quad 23,46 \%$ e $27,13 \%$, respectivamente.
Nesse sentido, o desenvolvimento de políticas públicas que incentivem a produção agrícola pode ser uma maneira de ampliar a arrecadação tributária, visto que contribui diretamente com o retorno financeiro recebido pelos municípios com a repartição do ICMS.

\section{CONCLUSÃO}

Este estudo teve por objetivo mensurar a produção primária na Região do Vale do Taquari (VT) e identificar sua importância na formação da receita orçamentária dos municípios em decorrência da transferência de 
recursos recebidos do Estado através da cotaparte do ICMS.

A análise dos dados indicou que o ICMS é uma das principais fontes de receita dos municípios do VT, a qual está vinculada com a sua capacidade de geração de valor agregado, visto que a forma de rateio do ICMS entre os municípios baseia-se em critérios de desempenho da economia municipal, entre os quais se destaca o VAF.

No período de 2007 a 2009, o VAF da Região apresentou um crescimento médio anual de $8 \%$, demonstrando um desempenho favorável. No entanto, em termos relativos, sua análise indicou a existência de disparidades significativas intermunicipais, visto que mais da metade desse valor foi gerado em apenas cinco municípios, enquanto que a maior parte dos demais municípios contribuiu pouco para a formação do VAF regional, pois possuem uma atividade econômica baseada em atividades primárias com baixo valor agregado (em 30,6\% dos municípios essa atividade foi responsável por mais de $80 \%$ do VAF municipal). Além disso, também se observou que este quadro de desigualdades se intensificou ao longo do período em estudo.

Entretanto, como a produção primária influencia no retorno do ICMS por meio de três critérios de repartição, ela contribui de forma significativa no retorno financeiro recebido pelos municípios através da transferência do ICMS. Em 2011, essa receita foi responsável, em média, por $27,22 \%$ das receitas municipais na Região.

Assim, em geral, a arrecadação do FPM e do ICMS representa as principais receitas municipais, em especial, nos municípios menores, onde as atividades urbanas são menos desenvolvidas. A arrecadação do FPM se baseia nas estimativas da população divulgadas pelo Instituto Brasileiro de Geografia e Estatística (IBGE), o que impossibilita que os administradores influenciem no seu repasse. Entretanto, a municipalidade pode desenvolver políticas públicas direcionadas ao incremento das atividades produtivas nos municípios, de forma a alterar sua participação na divisão do ICMS. E, dada à importância do setor primário para a geração de renda dos municípios da
Região em estudo, sugere-se 0 desenvolvimento de políticas públicas que possam incentivar o desenvolvimento dessa atividade, de modo a contribuir com 0 aumento das arrecadações municipais e assim, buscar reduzir, inclusive, as disparidades regionais.

\section{REFERÊNCIAS}

BRASIL. Lei n 4.320 , de 17 de março de 1964. Estatui Normas Gerais de Direito Financeiro para elaboração e controle dos orçamentos e balanços da União, dos Estados, dos Municípios e do Distrito Federal. Diário Oficial da União, Brasília, DF, 1964. Disponível em:<http://www.planalto.gov.br/ccivil_03/leis/L4 320.htm>. Acesso em: 18 nov. 2011.

Ministério da Fazenda. Secretaria do Tesouro Nacional. Manual de Contabilidade Aplicada ao Setor Público: parte I procedimentos contábeis orçamentários. 4. ed. Brasília, DF, 2011. Disponivel em:<http://goo.gl/c9zSt>. Acesso em:1 mar. 2012.

GIAMBIAGI, Fabio; ALÉM, Ana Cláudia. Finanças públicas: teoria e prática no Brasil. 3. ed. Rio de Janeiro: Elsevier, 2008.

INSTITUTO BRASILEIRO DE GEOGRAFIA E ESTATÍSTICA. Censo Agropecuário 2009. Rio de Janeiro, 2009. Disponível em:<http://www.ibge.gov.br>. Acesso em: 1 mar. 2012.

Censo Demográfico 2010. Rio de Janeiro, $2010 . \quad$ Disponível em:<www.ibge.gob.br>. Acesso em: 1 mar. 2012.

MONASTÉRIO, Leonardo Monteiro. Os critérios de retorno do ICMS no Rio Grande do Sul: análise econômica e espacial da PEC 228/04. Indicadores Econômicos FEE, Porto Alegre, v. 32, n. 3, p. 63-76, 2004.

PEREIRA, José Matias. Finanças públicas: a política orçamentária no Brasil. São Paulo: Atlas, 2006. 
PINHEIRO, Tiago Cisalpino. Hierarquia urbana e situação fiscal dos municípios brasileiros. Revista Brasileira de Estudos Regionais e Urbanos, Recife, 2009. Disponível em:<http://www.revistaaber.com.br/index.php/a ber/article/viewFile/70/32>. Acesso em: 5 mar. 2012.

RIO GRANDE DO SUL. Secretaria da Fazenda. Lei $n^{0} 11.038$ de 14 de novembro de 1997. Dispõe sobre a parcela do produto da arrecadação do Imposto sobre Operações Relativas à Circulação de Mercadorias e sobre Prestações de Serviços de Transporte Interestadual e Intermunicipal e de Comunicação (ICMS) pertencente aos municípios. Diário Oficial do Estado, Porto Alegre, $\quad 1997 . \quad$ Disponível em:<http://www.bvsde.paho.org/bvsacd/cd38/B rasil/L11038.pdf>. Acesso em: 18 nov. 2011.

\section{UNIVATES. Banco de Dados Regional.} Lajeado, RS, [20--?]. Disponível em:<http://www.univates.br/bdr>. Acesso em: 1 mar. 2012.

Perfil do Vale do Taquari. Lajeado, RS, set. 2011.
Adalberto Schnorrenberger

Administrador

Doutor em Agronegócio pela Universidade Federal do Rio Grande do Sul (UFRGS)

Professor do Centro Universitário Univates

E-mail: betoschn@univates.br

\section{Julia Elisabete Barden}

Economista

Doutora em Economia pela Universidade Federal do Rio Grande do Sul (UFRGS)

Professora do Centro Universitário Univates

E-mail: jbarden@univates.br

\section{Lucildo Ahlert}

Economista

Mestre em Engenharia de Produção pela Universidade

Federal de Santa Maria (UFSM)

Professor do Centro Universitário Univates

E-mail: lahlert@univates.br

\section{Fernanda Cristina Wiebusch Sindelar}

Economista

Doutoranda em Ambiente e Desenvolvimento no Centro Universitário Univates

Professora do Centro Universitário Univates

E-mail: fernanda@univates.br

\section{Samuel Martim de Conto}

Economista

Mestre em Administração pela Universidade Federal do rio Grande do Sul (UFRGS)

Professor do Centro Universitário Univates

E-mail: samuelc@univates.br

\section{Centro Universitário Univates}

Rua Avelino Tallini, 171, Bairro Universitário Lajeado/RS - CEP 95900-000 


\section{APÊNDICE A - IMPORTÂNCIA DO ICMS NA RECEITA ORÇAMENTÁRIA DOS MUNICÍPIOS DO VT} EM 2009

\begin{tabular}{|c|c|c|c|}
\hline MUNICIPIO & Receita Orçamentária & Cota ICMS & $\begin{array}{l}\text { Participação do ICMS } \\
\text { na Receita municipal }\end{array}$ \\
\hline Anta Gorda & $14.780 .028,77$ & $3.793 .394,09$ & $25,67 \%$ \\
\hline Arroio do Meio & $33.513 .150,20$ & 11.124.139,03 & $33,19 \%$ \\
\hline Arvorezinha & $17.409 .396,65$ & $3.920 .863,20$ & $22,52 \%$ \\
\hline Bom Retiro do Sul & $15.288 .677,12$ & $3.621 .555,53$ & $23,69 \%$ \\
\hline Canudos do Vale & 7.417.739,86 & $1.771 .194,65$ & $23,88 \%$ \\
\hline Capitão & $10.664 .616,18$ & $4.306 .029,24$ & $40,38 \%$ \\
\hline Colinas & $11.372 .482,54$ & $2.764 .403,32$ & $24,31 \%$ \\
\hline Coqueiro Baixo & $7.557 .225,52$ & $2.203 .109,37$ & $29,15 \%$ \\
\hline Cruzeiro do Sul & $18.066 .717,75$ & $5.874 .490,71$ & $32,52 \%$ \\
\hline Dois Lajeados & $10.503 .203,24$ & $2.815 .859,56$ & $26,81 \%$ \\
\hline Doutor Ricardo & $9.115 .581,21$ & $1.714 .676,35$ & $18,81 \%$ \\
\hline Encantado & $38.594 .827,68$ & $8.829 .245,16$ & $22,88 \%$ \\
\hline Estrela & $50.617 .046,43$ & 13.383.433,06 & $26,44 \%$ \\
\hline Fazenda Vilanova & $9.290 .043,00$ & $2.757 .262,00$ & $29,68 \%$ \\
\hline Forquetinha & $7.917 .950,56$ & $1.774 .810,26$ & $22,42 \%$ \\
\hline \|ópolis & $10.218 .052,51$ & $2.036 .297,80$ & $19,93 \%$ \\
\hline Imigrante & $12.096 .184,74$ & $4.054 .040,21$ & $33,52 \%$ \\
\hline Lajeado & $101.326 .673,32$ & $23.386 .692,48$ & $23,08 \%$ \\
\hline Marques de Souza & $11.009 .845,03$ & $2.478 .382,51$ & $22,51 \%$ \\
\hline Muçum & $9.537 .580,76$ & $2.351 .354,80$ & $24,65 \%$ \\
\hline Nova Bréscia & $12.816 .590,20$ & $4.955 .134,61$ & $38,66 \%$ \\
\hline Paverama & $13.899 .811,00$ & $2.651 .326,00$ & $19,07 \%$ \\
\hline Poço das Antas & $7.089 .397,10$ & $2.101 .810,25$ & $29,65 \%$ \\
\hline Pouso Novo & $8.293 .603,29$ & $1.630 .656,37$ & $19,66 \%$ \\
\hline Progresso & $19.342 .874,23$ & $3.458 .623,86$ & $17,88 \%$ \\
\hline Putinga & $14.764 .797,22$ & $2.791 .225,41$ & $18,90 \%$ \\
\hline Relvado & $8.119 .973,69$ & $2.447 .285,10$ & $30,14 \%$ \\
\hline Roca Sales & 17.305.189,09 & $7.073 .573,40$ & $40,88 \%$ \\
\hline Santa Clara do Sul & $11.269 .246,35$ & $3.029 .414,79$ & $26,88 \%$ \\
\hline Sério & $8.224 .394,95$ & $1.940 .608,01$ & $23,60 \%$ \\
\hline Tabaí & $8.640 .031,00$ & $1.824 .767,00$ & $21,12 \%$ \\
\hline Taquari & $31.139 .940,13$ & $8.873 .626,67$ & $28,50 \%$ \\
\hline Teutônia & $43.525 .948,26$ & $14.354 .148,74$ & $32,98 \%$ \\
\hline Travesseiro & $9.270 .698,74$ & $2.955 .457,36$ & $31,88 \%$ \\
\hline Vespasiano Correa & 7.477.347,21 & $2.379 .034,55$ & $31,82 \%$ \\
\hline Westfalia & $11.869 .194,38$ & $5.022 .002,94$ & $42,31 \%$ \\
\hline
\end{tabular}

Fonte: BRASIL. Ministério da Fazenda. Secretaria do Tesouro Nacional. Manual de Contabilidade Aplicada ao Setor Público: parte I - procedimentos contábeis orçamentários. 4. ed. Brasília, DF, 2011. Disponível em:〈http://goo.gl/c9zSt>. Acesso em:1 mar. 2012. 
APÊNDICE B - VALOR ADICIONADO FISCAL DOS MUNICÍPIOS DO VT ENTRE 2007-2009

\begin{tabular}{|c|c|c|c|c|c|c|c|}
\hline \multirow{2}{*}{ Município } & \multicolumn{3}{|c|}{ Valor Adicionado Fiscal } & \multicolumn{4}{|c|}{ Evolução do VAF em \% } \\
\hline & 2007 & 2008 & 2009 & $\begin{array}{c}2007 \text { a } \\
2008\end{array}$ & $\begin{array}{c}2008 \mathrm{a} \\
2009\end{array}$ & $\begin{array}{c}2007 a \\
2009\end{array}$ & $\begin{array}{l}\text { Média } \\
\text { anual }\end{array}$ \\
\hline Anta Gorda & $75.698 .019,95$ & $82.149 .105,00$ & $85.521 .988,00$ & 8,52 & 4,11 & 12,98 & 6,29 \\
\hline Arroio do Meio & $343.412 .507,47$ & $310.756 .813,00$ & $394.403 .644,00$ & $-9,51$ & 26,92 & 14,85 & 7,17 \\
\hline Arvorezinha & 73.917.129,06 & $86.113 .935,00$ & $94.888 .703,00$ & 16,50 & 10,19 & 28,37 & 13,30 \\
\hline Bom Retiro do Sul & $85.241 .717,10$ & $83.110 .929,00$ & $115.614 .254,00$ & $-2,50$ & 39,11 & 35,63 & 16,46 \\
\hline Canudos do Vale & $16.689 .064,62$ & $25.791 .936,00$ & $28.273 .201,00$ & 54,54 & 9,62 & 69,41 & 30,16 \\
\hline Capitão & $64.423 .564,77$ & $79.651 .995,00$ & $87.402 .276,00$ & 23,64 & 9,73 & 35,67 & 16,48 \\
\hline Colinas & $33.616 .202,43$ & $40.811 .777,00$ & 43.896.602,00 & 21,41 & 7,56 & 30,58 & 14,27 \\
\hline Coqueiro Baixo & $35.509 .776,97$ & $42.092 .307,00$ & $41.457 .635,00$ & 18,54 & $-1,51$ & 16,75 & 8,05 \\
\hline Cruzeiro do Sul & 125.913.145,49 & $168.653 .113,00$ & $165.380 .577,00$ & 33,94 & $-1,94$ & 31,34 & 14,61 \\
\hline Dois Lajeados & $52.380 .547,46$ & $58.408 .549,00$ & $63.180 .040,00$ & 11,51 & 8,17 & 20,62 & 9,83 \\
\hline Doutor Ricardo & $25.652 .894,63$ & $24.747 .542,00$ & $27.896 .438,00$ & $-3,53$ & 12,72 & 8,75 & 4,28 \\
\hline Encantado & $236.409 .171,14$ & $265.975 .107,00$ & $296.879 .486,00$ & 12,51 & 11,62 & 25,58 & 12,06 \\
\hline Estrela & $351.091 .559,64$ & $425.195 .176,00$ & $451.469 .319,00$ & 21,11 & 6,18 & 28,59 & 13,40 \\
\hline Fazenda Vilanova & $72.090 .958,77$ & $63.022 .990,00$ & $89.826 .076,00$ & $-12,58$ & 42,53 & 24,60 & 11,62 \\
\hline Forquetinha & $24.501 .844,69$ & $29.581 .930,00$ & $29.419 .825,00$ & 20,73 & $-0,55$ & 20,07 & 9,58 \\
\hline Ilópolis & $34.919 .120,66$ & $37.477 .939,00$ & $38.918 .043,00$ & 7,33 & 3,84 & 11,45 & 5,57 \\
\hline Imigrante & $81.301 .723,44$ & $105.480 .014,00$ & $92.866 .973,00$ & 29,74 & $-11,96$ & 14,23 & 6,88 \\
\hline Lajeado & $713.070 .332,40$ & $849.856 .805,00$ & $934.582 .048,00$ & 19,18 & 9,97 & 31,06 & 14,48 \\
\hline Marques de Souza & $41.877 .749,55$ & 41.104.729,00 & $48.811 .561,00$ & $-1,85$ & 18,75 & 16,56 & 7,96 \\
\hline Muçum & $43.950 .989,25$ & $63.631 .004,00$ & $30.744 .762,00$ & 44,78 & $-51,68$ & $-30,05$ & $-16,36$ \\
\hline Nova Bréscia & $84.532 .205,72$ & $100.030 .918,00$ & $99.555 .285,00$ & 18,33 & $-0,48$ & 17,77 & 8,52 \\
\hline Paverama & $41.082 .462,61$ & $43.250 .881,00$ & 49.584.501,00 & 5,28 & 14,64 & 20,70 & 9,86 \\
\hline Poço das Antas & $26.669 .469,00$ & $31.574 .111,00$ & $28.404 .654,00$ & 18,39 & $-10,04$ & 6,51 & 3,20 \\
\hline Pouso Novo & $27.223 .222,93$ & $23.507 .439,00$ & $29.198 .478,00$ & $-13,65$ & 24,21 & 7,26 & 3,56 \\
\hline Progresso & $57.361 .775,24$ & $70.252 .207,00$ & $68.577 .335,00$ & 22,47 & $-2,38$ & 19,55 & 9,34 \\
\hline Putinga & 46.264.721,91 & $58.640 .501,00$ & $58.953 .091,00$ & 26,75 & 0,53 & 27,43 & 12,88 \\
\hline Relvado & $38.609 .877,31$ & $43.686 .736,00$ & $46.123 .726,00$ & 13,15 & 5,58 & 19,46 & 9,30 \\
\hline Roca Sales & $242.668 .704,43$ & $134.387 .989,00$ & $197.716 .654,00$ & $-44,62$ & 47,12 & $-18,52$ & $-9,74$ \\
\hline Santa Clara do Sul & $47.664 .960,39$ & $58.864 .609,00$ & $67.905 .925,00$ & 23,50 & 15,36 & 42,47 & 19,36 \\
\hline Sério & $26.135 .460,19$ & $32.921 .873,00$ & $28.076 .809,00$ & 25,97 & $-14,72$ & 7,43 & 3,65 \\
\hline Tabaí & $24.622 .353,57$ & $28.408 .161,00$ & $30.576 .573,00$ & 15,38 & 7,63 & 24,18 & 11,44 \\
\hline Taquari & $271.881 .835,81$ & $257.451 .457,00$ & $212.405 .248,00$ & $-5,31$ & $-17,50$ & $-21,88$ & $-11,61$ \\
\hline Teutônia & $412.745 .107,78$ & $476.074 .647,00$ & $448.845 .017,00$ & 15,34 & $-5,72$ & 8,75 & 4,28 \\
\hline Travesseiro & $42.423 .176,42$ & $50.509 .542,00$ & $45.449 .459,00$ & 19,06 & $-10,02$ & 7,13 & 3,51 \\
\hline Vespasiano Correa & $38.227 .990,84$ & $45.872 .200,00$ & $44.280 .095,00$ & 20,00 & $-3,47$ & 15,83 & 7,63 \\
\hline Westfália & $88.449 .703,03$ & $109.539 .750,00$ & $104.829 .834,00$ & 23,84 & $-4,30$ & 18,52 & 8,87 \\
\hline Total & 4.048.231.046,67 & 4.448.586.716,00 & $4.721 .916 .135,00$ & 9,89 & 6,14 & 16,64 & 8,00 \\
\hline
\end{tabular}

Fonte: STN (BRASIL, 2011). 


\section{APÊNDICE C - EVOLUÇÃO DA PRODUÇÃO PRIMÁRIA DOS MUNICÍPIOS DO VT ENTRE 2007 E 2009}

\begin{tabular}{|c|c|c|c|c|c|c|c|}
\hline \multirow{2}{*}{ Município } & \multicolumn{3}{|c|}{ Valor da produção primária } & \multicolumn{4}{|c|}{ Evolução do VDP em \% } \\
\hline & 2007 & 2008 & 2009 & $\begin{array}{c}2007 \\
a \\
2008 \\
\end{array}$ & $\begin{array}{c}2008 \\
a \\
2009 \\
\end{array}$ & \begin{tabular}{|c|}
2007 \\
$a$ \\
2009 \\
\end{tabular} & $\begin{array}{l}\text { Média } \\
\text { anual }\end{array}$ \\
\hline Anta Gorda & $51.501 .424,00$ & $58.582 .044,45$ & $55.255 .004,66$ & 13,75 & $-5,68$ & 7,29 & 3,58 \\
\hline Arroio do Meio & $78.360 .980,00$ & $89.479 .757,75$ & $80.923 .647,45$ & 14,19 & $-9,56$ & 3,27 & 1,62 \\
\hline Arvorezinha & $50.314 .719,00$ & $60.133 .814,06$ & $62.901 .461,59$ & 19,52 & 4,60 & 25,02 & 11,81 \\
\hline Bom Retiro do Sul & $20.461 .425,00$ & $20.630 .904,32$ & $22.283 .425,93$ & 0,83 & 8,01 & 8,90 & 4,36 \\
\hline Canudos do Vale & $15.268 .751,00$ & $24.406 .058,74$ & $26.391 .772,04$ & 59,84 & 8,14 & 72,85 & 31,47 \\
\hline Capitão & $59.414 .949,00$ & 74.61 & 82.626 & 25,58 & 10,74 & 39,07 & 17,93 \\
\hline Colinas & $26.928 .826,00$ & 34.5 & 37.662 & 28,34 & 8,97 & 39,86 & 18,26 \\
\hline Coqueiro Baixo & $34.043 .310,00$ & 40.426 & 39.8 & 18,75 & $-1,45$ & 17,03 & 8,18 \\
\hline Cruzeiro do Sul & $47.057 .546,00$ & $60.383 .721,14$ & 63.62 & 28,32 & 5,38 & 35,22 & 16,28 \\
\hline Dois Lajeados & $41.365 .613,00$ & $51.261 .351,81$ & $48.156 .510,37$ & 23,92 & $-6,06$ & 16,42 & 7,90 \\
\hline Doutor Ricardo & $19.910 .805,00$ & $17.930 .258,76$ & $19.817 .599,16$ & $-9,95$ & 10,53 & $-0,47$ & $-0,23$ \\
\hline Encantado & $73.576 .757,00$ & $82.004 .922,64$ & $81.561 .315,91$ & 11,45 & $-0,54$ & 10,85 & 5,29 \\
\hline Estrela & $87.362 .773,00$ & $107.988 .301,16$ & 109.13 & 23,61 & 1,06 & 24,92 & 11,77 \\
\hline Fazenda Vilanova & & & & & 12,62 & 78 & \\
\hline Forquetinha & & & & 40,16 & $-1,37$ & 38,24 & 17,57 \\
\hline Ilópolis & & & & 15,11 & 8,27 & 24,63 & 11,64 \\
\hline Imigrante & 32.7 & 24 & 3,78 & 22,50 & 12,65 & 38,00 & 17,47 \\
\hline Lajeado & $13.157 .683,00$ & $19.034 .880,09$ & $13.327 .263,74$ & 44,67 & $-29,99$ & 1,29 & 0,64 \\
\hline Marques de Souza & $31.431 .961,00$ & $31.997 .837,11$ & $37.231 .223,15$ & 1,80 & 16,36 & 18,45 & 8,83 \\
\hline Muçum & $11.426 .396,00$ & $11.382 .434,99$ & $13.511 .173,40$ & $-0,38$ & 18,70 & 18,25 & 8,74 \\
\hline Nova Bréscia & $77.984 .651,00$ & $93.331 .945,45$ & $92.204 .434,91$ & 19,68 & $-1,21$ & 18,23 & 8,74 \\
\hline Paverama & $19.620 .480,00$ & $23.907 .706,92$ & $23.792 .801,28$ & 21,85 & $-0,48$ & 21,27 & 10,12 \\
\hline Poço das A & & & & 25,97 & \begin{tabular}{|l|}
$-13,52$ \\
\end{tabular} & 8,94 & 420 \\
\hline Pouso Novo & & & & & 22,87 & 8,59 & 4,20 \\
\hline Progresso & & & & 27,15 & $-2,90$ & 23,46 & 11,11 \\
\hline Putinga & $35.593 .331,00$ & $45.258 .064,61$ & $45.563 .924,29$ & 27,15 & 0,68 & 28,01 & 13,14 \\
\hline Relvado & $35.342 .170,00$ & $39.964 .652,47$ & $42.562 .047,83$ & 13,08 & 6,50 & 20,43 & 9,74 \\
\hline Roca Sales & $60.012 .218,00$ & $74.116 .859,52$ & $75.272 .504,71$ & 23,50 & 1,56 & 25,43 & 11,99 \\
\hline Santa Clara do Sul & $19.391 .394,00$ & $25.024 .931,32$ & $25.413 .800,15$ & 29,05 & 1,55 & 31,06 & 14,48 \\
\hline Sério & $24.004 .821,00$ & $30.651 .817,07$ & $25.496 .190,66$ & 27,69 & $-16,82$ & 6,21 & 3,06 \\
\hline Tabaí & $15.423 .883,00$ & $18.790 .689,23$ & $20.426 .266,02$ & 21,83 & 8,70 & 32,43 & 15,08 \\
\hline Taquari & $37.744 .076,00$ & $37.010 .630,61$ & $35.951 .288,64$ & $-1,94$ & $-2,86$ & $-4,75$ & $-2,40$ \\
\hline Teutônia & $66.329 .881,00$ & $84.132 .089,63$ & $88.457 .778,07$ & 26,84 & 5,14 & 33,36 & 15,48 \\
\hline Travesseiro & $36.106 .516,00$ & $42.724 .675,06$ & $39.282 .741,92$ & 18,33 & $-8,06$ & 8,80 & 4,31 \\
\hline Vespasiano Correa & $32.633 .645,00$ & $41.639 .318,73$ & $40.175 .375,74$ & 27,60 & $-3,52$ & 23,11 & 10,96 \\
\hline Westfália & $52.298 .313,00$ & $66.366 .605,36$ & $67.952 .203,37$ & 26,90 & 2,39 & 29,93 & 13,99 \\
\hline Total & $1.353 .201 .171,00$ & $1.622 .714 .624,28$ & $1.640 .406 .116,67$ & 19,92 & 1,09 & 21,22 & 10,10 \\
\hline
\end{tabular}

Fonte: STN (BRASIL, 2011). 